\title{
Prevalence of Transfusion Transmissible Infections in Donors and Utilization of Blood and Components in a Tertiary Care Hospital
}

\author{
Varsha T. ${ }^{1}$, Ashwini K. ${ }^{2}$, Uma Maheswaran E. ${ }^{3}$ \\ ${ }^{1}$ Under Graduate Student, Department of Pathology, Government Medical College, Omandurar, Chennai, Tamilnadu, \\ India. ${ }^{2}$ Assistant Professor, Department of Pathology, Government Medical College, Omandurar, Chennai, Tamilnadu, \\ India. ${ }^{3}$ Medical Officer, Blood Bank, Institute of Social Obstetrics and Government Kasturba Gandhi Hospital for \\ Women and Children, Triplicane, Chennai, Tamilnadu, India.
}

\section{ABSTRACT}

\section{BACKGROUND}

Blood transfusion has hazards of Transfusion Transmissible Infections (TTI). Blood has several components whose separation, storage and utilization has brought down adverse reactions in recipients. This study aims at evaluating the prevalence of TTI in donors and the pattern of utilization of blood and its components in a tertiary care hospital.

\section{METHODS}

This is a retrospective descriptive study done between January to December 2017. Data regarding the screening of blood, component separation, storage, utilization and discarding was collected and analysed.

\section{RESULTS}

Out of 4158 donations screened, prevalence of TTI was $38(0.9 \%)$ and that of HBV and HCV was $36(0.86 \%)$ and $2(0.04 \%)$. None of them were positive for HIV, Syphilis and Malaria. Total blood units collected were 10,184. PRBC (32.87\%) was the most utilized component followed by FFP (30.59\%), Platelet $(26.18 \%)$, WB $(10.33 \%)$ and Cryoprecipitate $(0.04 \%)$. Obstetric $(45.42 \%)$ cases were most benefited. Out of 143 units discarded, 84 units (58.74\%) were discarded due to sero-positivity.

\section{CONCLUSIONS}

This study analyses the prevalence of TTIs in a tertiary care centre over a period of one year and also emphasizes the appropriate and judicious use of blood and blood components.

\section{KEY WORDS}

Seroprevalence, Component Separation, TTI
Corresponding Author:

Dr. Ashwini K.,

Assistant Professor,

Department of Pathology,

Government Medical College,

Omandurar Estate, Chennai,

Tamilnadu, India.

E-mail:dr.achu15@gmail.com

DOI: $10.14260 / j e m d s / 2019 / 678$

Financial or Other Competing Interests: None.

How to Cite This Article:

Varsha T, Ashwini K, Maheswaran UE. Prevalence of transfusion transmissible infections in donors and utilization of blood and components in a tertiary care hospital. J. Evolution Med. Dent. Sci. 2019;8(42):3125-3129, DOI: $10.14260 /$ jemds/2019/678

Submission 14-08-2019, Peer Review 02-10-2019,

Acceptance 09-10-2019,

Published 21-10-2019. 


\section{BACKGROUND}

Blood transfusion is a life-saving intervention in patient management within the health care systems ${ }^{[1]}$. Complications still occur but most are minor and transient. The most common is the febrile nonhemolytic reaction. Other transfusion reactions are rare but can have fatal consequences. These are Allergic reactions, Haemolytic reactions, Transfusion- Related Acute Lung Injury (TRALI) and Infectious Complications. Hypersensitivity reactions and direct or residual risk associated with a spectrum of transfusion- transmissible infections are the major concerns [2]. WHO recommends the integrated strategy of qualityassured screening of all donated blood for transfusiontransmissible infections, including HIV, hepatitis B, hepatitis C, Treponema pallidum (Syphilis) and other infections such as Trypanosoma cruzi (Chagas Disease) and Plasmodium species (Malaria); as well as testing for blood groups and compatibility.[2] According to World Health Organization (WHO) 2018 report, globally, 36.9 million people are estimated to be living with $\mathrm{HIV}^{[3]}$ and 325 million people are estimated to be living with Viral Hepatitis B and C in 2017.[4] According to 2012 report, the global prevalence of syphilis in adult men and women were $0.49 \%(0.4-0.6 \%)$ and $0.48(0.3-$ 0.7\%).[5] According to 2019 report, the global prevalence of malaria was estimated to be 219 million cases.[6] Blood consists of different blood cells suspended in plasma.[7] Blood transfusion was first performed successfully by James Blundell in 1818.[8] Blood has become scarce resource because of advances in blood bank techniques, increased frequency of complex surgical procedures, aging populations, initiatives aimed at improving health care standards and decrease in donor availability due to stringent screening criteria.[9] Studies have revealed high proportion of inappropriate use of blood transfusion often in both developed and developing countries.[8,10] This study aims to evaluate the prevalence of TTI in donors in blood bank of Institute of Social Obstetrics and Government Kasturba Gandhi Hospital for Women and Children, Triplicane, Chennai, India over a period of one year. This study also aims at evaluating the pattern of utilization of blood and components in a tertiary care hospital, tries to bring down the excess usage and discard of blood and components.

\section{METHODS}

\section{Study Design and Site}

A retrospective descriptive study on donations that were done from January 2017 to December 2017 was performed. The study was undertaken at the Blood Bank of Institute of Social Obstetrics and Government Kasturba Gandhi Hospital for Women and Children, Triplicane, Chennai, Tamilnadu, India. The blood bank receives on an average of 10,000 donations per year.

\section{Study Population}

The study population includes all donors who donated blood from January 2017 to December 2017. The donor population includes voluntary donors. Voluntary donors were walk in donors, students and employees of the institution and from blood donation camps. The donors who fulfil the criteria as recognized by Ministry of Health, Government of India are only included in the study.

\section{Donor Selection and Screening of Donated Blood}

Donors were asked to fill donor details questionnaire which included details regarding their medical history. Donors were then examined by checking their Pulse and Blood Pressure. Blood was collected by phlebotomy under aseptic conditions from collection bags. $5 \mathrm{ml}$ of blood is withdrawn from collection bags using syringe. The withdrawn blood was labelled and centrifuged to separate serum from the blood. The serum was then subjected to serological tests. The methods used to screen were ELISA for HIV, Hepatitis B and Hepatitis C, VDRL for Syphilis, Rapid Card test for Malaria. The tests were performed in strict compliance based on existing national testing policies and guidelines. Sero-positive samples were discarded, and details were recorded in the registers. The data regarding donations and laboratory investigations were collected from the blood bank registers using an approved data proforma.

\section{Component Separation and Utilization}

The blood was collected either in single, double, triple or quadruple blood bags according to the needs and demand. Single bags were used to collect Whole Blood and stored at $2^{\circ} \mathrm{C}$ to $6^{\circ} \mathrm{C}$ for 35 days. Double bags were used to collect Packed Red Blood Cells and Plasma. Of which, plasma was centrifuged using refrigerated centrifuge at $3500 \mathrm{rpm}$ for 12 minutes at $4^{\circ} \mathrm{C}$, extracted out and stored at $-40^{\circ} \mathrm{C}$ or $-80^{\circ} \mathrm{C}$ for 1 year in deep freezer. Triple bags were used to collect Packed Red Blood Cells, Fresh Frozen Plasma and Platelet. Platelets were extracted by refrigerated centrifuge and stored in platelet agitator at $22^{\circ} \mathrm{C}$ for 5 days. Quadruple bags were used to collect Packed Red Blood Cells, Fresh Frozen Plasma, Platelets and Cryoprecipitate. Fresh Frozen Plasma is thawed at $5^{\circ} \mathrm{C}$ for 6 to 8 hours, centrifuged at $2000 \mathrm{rpm}$ for 8 minutes at $4^{\circ} \mathrm{C}$ and utilized immediately or stored at $-40^{\circ} \mathrm{C}$. The blood and blood components were utilized mainly in obstetrics and paediatrics followed by other departments. The data regarding the collection, utilization and discard of various blood and blood components were collected from the blood bank registers using an approved data proforma.

\section{Ethical Considerations}

Ethical clearance was obtained from the Institutional Ethics Committee, Government Medical College, Omandurar Estate, Chennai, Tamil Nadu, India. The permission from head of the institution and chief medical officer of blood bank was also obtained. This study was carried out using the data documented in the blood bank registers and donors were not involved directly in the study at any instance. The donor confidentiality was maintained throughout the study.

\section{Statistical Analysis}

The data were entered into MS Excel 2016, analysed and the report was presented in the form of tables and percentage. The prevalence of Transmissible Transfusion Infections (TTI) were calculated by dividing the number of seropositive blood donations with the total number of donations that were collected during 2017. The prevalence of HIV, Hepatitis B and C, Syphilis and Malaria were expressed in percentage 
individually and in accordance with months. The blood and blood components collection, utilization and discard were correlated with each component. Utilization of blood components were correlated among maternity, neonatal and other departments. Discard of blood components were correlated among various reasons of discard.

\section{RESULTS}

A total of 4158 donations were received from January 2017 to December 2017. Out of these, $4119(99 \%)$ were males and $39(1 \%)$ were females. Maximum donations were received in the month of May which is $11.2 \%$ (466 donations). Out of 4158 donations, 38(0.9\%) were positive for Transfusion Transmissible Infections (TTI). The prevalence of Transfusion Transmissible Infections (TTI) in 2017 is $0.9 \%$ (38 donations). The prevalence is $0.86 \%$ (36 donations) and $0.04 \%$ ( 2 donations) for Hepatitis B and C respectively. None of them were positive for HIV, Syphilis and Malarial parasite. The prevalence of TTI, Hepatitis B and C with respect to months in 2017 are depicted in Table 1.

\begin{tabular}{|c|c|c|c|c|}
\hline Month of & No. of Donors & \multicolumn{3}{|c|}{ Frequency of TTI (\%) } \\
\cline { 3 - 5 } Donation & $(\%)$ & HBV & HCV & Total \\
\hline January & $264(6.4)$ & $2(0.04)$ & 0 & $2(0.04)$ \\
\hline February & $464(11.1)$ & $3(0.07)$ & $1(0.02)$ & $4(0.1)$ \\
\hline March & $217(5.2)$ & $2(0.04)$ & 0 & $2(0.04)$ \\
\hline April & $427(10.3)$ & $2(0.04)$ & 0 & $2(0.04)$ \\
\hline May & $466(11.2)$ & $3(0.07)$ & 0 & $3(0.07)$ \\
\hline June & $327(7.9)$ & $3(0.07)$ & $1(0.02)$ & $4(0.1)$ \\
\hline July & $311(7.5)$ & $1(0.02)$ & 0 & $1(0.02)$ \\
\hline August & $363(8.7)$ & $5(0.12)$ & 0 & $5(0.12)$ \\
\hline September & $297(7.1)$ & $3(0.07)$ & 0 & $3(0.07)$ \\
\hline October & $372(8.9)$ & $3(0.07)$ & 0 & $3(0.07)$ \\
\hline November & $261(6.3)$ & $5(0.12)$ & 0 & $5(0.12)$ \\
\hline December & $389(9.4)$ & $4(0.1)$ & 0 & $4(0.1)$ \\
\hline Total & 4158 & $36(0.86)$ & $2(0.04)$ & $38(0.9)$ \\
\hline Table 1. Prevalence of TTI with Respect to Month of Donation among \\
Blood Donors at Blood Bank, Institute of Social Obstetrics and \\
Government Kasturba Gandhi Hospital for Women and Children, \\
Triplicane, Chennai, Tamilnadu, India \\
\hline
\end{tabular}

Prevalence of TTI reported is more in August and November $0.12 \%$ (5 donations) and less in July $0.02 \%$ (1 donation). Prevalence of Hepatitis B reported is more in August and November $0.12 \%$ (5 donations) and less in July $0.02 \%$ ( 1 donation). Only 2 donations $(0.04 \%)$ were reported with Hepatitis C sero-positive in February and June respectively.

A total of 10184 blood components were prepared during the year 2017. Maximum number of blood units were collected in October which is $10.11 \%$ (1030 units). Minimum number of blood units were collected in March which is $5.67 \%$ (577 units). A total of 10576 components were utilized in the year 2017 which includes units collected in 2016 along with the units collected in the year 2017. On an average, 881 blood units were utilized per month. Maximum number of blood units were utilized in August which is $10.62 \%$ (1123 units). Minimum number of blood units were utilized in March which is $7.03 \%$ (743 units). Out of 10576 blood units utilized, 10.33\% (1092 units) were WB, 32.87\% (3476 units) were PRBC, 26.18\% (2769 units) were Platelet, 30.59\% (3235 units) were FFP, 0.04\% (4 units) were Cryoprecipitate.
9.6 times more blood components were used compared to Whole Blood utilization and this ensures effective utilisation of blood and its components. Only 4 units of Cryoprecipitate $(0.04 \%)$ were utilized in the month of December. This is depicted in Figure 1.

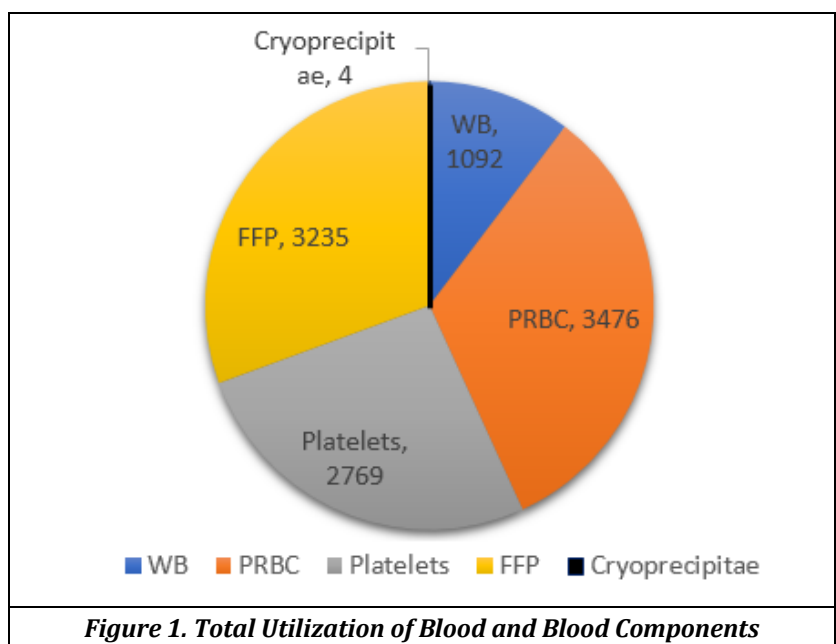

Figure 1. Total Utilization of Blood and Blood Components

The utilization of Whole Blood peaked in June, Packed Red Blood Cells and Fresh Frozen Plasma in August, Platelets in October and Cryoprecipitate in December. A total of 143 units were discarded in the year 2017 which includes units collected in December 2016 along with the units collected in the year 2017. Maximum number of blood units were discarded in November which is $15.38 \%$ (22 units). Minimum number of blood units were discarded in July which is $2.1 \%$ (3 units). Out of 143 blood units discarded, $17.48 \%$ were WB, $21.68 \%$ were PRBC, $37.76 \%$ were Platelets and $23.08 \%$ were FFP. No Cryoprecipitate units were discarded. A total of 5753 blood units were utilised at Institute of Social Obstetrics and Government Kasturba Gandhi Hospital for Women and Children, Triplicane, Chennai, Tamilnadu, India. Of which, majority of the blood units were issued to the department of Obstetrics which accounted for 2613 (45.42\%) units, followed by department of Paediatrics which accounted for 570 (9.9\%) units and the rest 2570 (44.67\%) units were supplied to other departments. This is depicted in Table 2.

\begin{tabular}{|c|c|c|}
\hline Departments & Total No. of Unit & Percentage (\%) \\
\hline Maternity & 2613 & 45.42 \\
\hline Neonatal & 570 & 9.9 \\
\hline Others & 2570 & 44.67 \\
\hline Total & 5753 & 100 \\
\hline \multicolumn{2}{|c|}{ Table 2. Number and Percentage of Blood Units Utilized by different }
\end{tabular}
Departments

\begin{tabular}{|c|c|c|c|c|c|}
\hline Reason & WB (\%) & PRBC (\%) & Platelet (\%) & FFP (\%) & Total (\%) \\
\hline $\begin{array}{c}\text { HBsAg } \\
\text { positive }\end{array}$ & $11(7.69)$ & $25(17.48)$ & $19(13.29)$ & $25(17.48)$ & $80(55.94)$ \\
\hline $\begin{array}{c}\text { Poor } \\
\text { collection }\end{array}$ & $7(4.9)$ & 0 & 0 & 0 & $7(4.9)$ \\
\hline $\begin{array}{c}\text { Date } \\
\text { expiry }\end{array}$ & $1(0.7)$ & $3(2.1)$ & $34(23.77)$ & 0 & $38(26.57)$ \\
\hline $\begin{array}{c}\text { Quality } \\
\text { control }\end{array}$ & $5(3.5)$ & $1(0.7)$ & 0 & 0 & $6(4.2)$ \\
\hline $\begin{array}{c}\text { HCV } \\
\text { Positive }\end{array}$ & $1(0.69)$ & $1(0.7)$ & $1(0.7)$ & $1(0.7)$ & $4(2.8)$ \\
\hline $\begin{array}{c}\text { Bag } \\
\text { Broken }\end{array}$ & 0 & $1(0.7)$ & 0 & $7(4.9)$ & $8(5.59)$ \\
\hline Total & $25(17.48)$ & $31(21.68)$ & $54(37.76)$ & $33(23.08)$ & $143(100)$ \\
\hline \multicolumn{7}{|c|}{ Table 3. Reasons for Discarding Blood and Blood Components } \\
\hline
\end{tabular}


Reasons for blood and blood components discard is depicted in Table 3. Of 143 blood units discarded, 55.94\% of the blood units were discarded due to HBsAg Positive followed by $26.57 \%$ of the blood units discarded due to Date expiry. The least blood units discarded were $2.8 \%$ due to HCV positivity. $58.74 \%$ of the blood units were discarded due to sero-positivity.

\section{DISCUSSION}

Out of 4158 blood units screened, 38 donors (0.9\%) were found positive for Transfusion Transmissible Infections (TTI). 36 donors $(0.86 \%)$ and 2 donors $(0.04 \%)$ were found to be positive for Hepatitis $\mathrm{B}$ and Hepatitis $\mathrm{C}$ respectively. In the study conducted by Nejat Siraj et al.,[2] a total of 60,236 consecutive blood donations were screened over a period of 7 years from 2010 to 2016; 3.6\% of donated blood was positive for at least one TTI and $0.1 \%$ donations showed evidence of multiple infections. $2 \%$ and $0.7 \%$ donors were tested positive for HBV and HCV respectively. Henshaw Uchechi Okoroiwu et al.,[11] conducted a study in a total of 24,979 prospective donors over a period of 12 years from 2005 to 2016 and found that 3739 units (14.96\%) were positive for at least one infective agent. $4.1 \%$ and $3.6 \%$ donors were positive for HBV and HCV respectively.

In our study, it was found that no donors were positive for HIV, Syphilis and Malarial parasite.

In our study, out of 10576 units, Packed Red Blood Cells (32.87\%) were the most utilized blood component followed by Fresh Frozen Plasma (30.59\%). This is similar to studies conducted by Bhag Chand Regar et al. [12] Zubair Qureshi et al. [13], Mathew AS et al.[14] Shruti K. Katkoria et al.[15] wherein PRBCs were the most utilized component accounting to $64.6 \%, 58.14 \%, 42.5 \%$ and $78.4 \%$ respectively.

In our study, 9.6 times more blood components were found to be utilized compared to Whole Blood transfusion. Whereas in the study conducted by Bhag Chand Regar et al.[12] out of 18,382 transfusions, 3585 were of Whole Blood and the rest were component transfusions, i.e., around 4.12 times more blood components were utilized when compared to Whole Blood transfusion.

In our study, most of the blood and components (45.42\%) units were utilized by Department of Obstetrics, which is similar to studies conducted by Henshaw Uchechi Okoroiwu et al.[16] Kafle SU et al.[17] Rahman MM et al..18] where $41.4 \%$, $39.8 \%$ and $41 \%$ of the blood components respectively were utilized by the Department of Obstetrics.

Out of 143 blood units discarded, 84 units (58.74\%) were discarded due to Sero-positivity, followed by 38 units (26.5\%) due to date expiry. This is similar to studies conducted by Kumar A et al.[19] and Arora I et al. [20] where the major reason for discard of blood and components was sero-positivity followed by date expiry.

\section{Limitations}

Data was collected in one centre which represents only a small proportion of the population. Being a retrospective study, data was collected from blood bank register while most of the socio-demographic data were missed and actual indication of transfusion could not be audited which can be considered as limitation.

\section{CONCLUSIONS}

Diminishing the prevalence of Transfusion Transmitted Infections (TTI) among blood donors remains an important goal in blood transfusion. Blood is a precious and scarce source of life-saving modality available in health care centres. Appropriate use of blood and blood components is thus necessary. This study emphasizes that the blood components need to be utilized appropriately with decreasing use of Whole Blood transfusion to avoid unnecessary exposure to donor antigens and immunologic consequences. This study showed that there was undesired discarding of blood units due to sero-positivity. This study highlights the importance of screening of blood products in order to prevent TTIs. More specific donor selection, advanced screening methods and strict transfusion guidelines should be established to decrease the prevalence of silent carriers of Hepatitis B and C. Prospective community-based studies with advanced methods may be performed to analyse the socio-demographic risk factors and to establish cause-effect relationship among them as the prevalence analysed in this study directly reflects the prevalence of Transfusion Transmitted Infections (TTI) in the general population. Awareness among the staff and vigilance shall be established to decrease the unwanted discarding of blood and components and to popularise costeffective transfusion practices. Prospective studies may be performed in two or more blood collection centres to analyse the utilization and discard rate of blood and blood components, and to audit the indications of transfusion among the several specialities.

\section{ACKNOWLEDGEMENT}

The authors are grateful to the staff of Blood Bank of Institute of Social Obstetrics and Government Kasturba Gandhi Hospital for Women and Children, Triplicane, Chennai, Tamilnadu, India for providing the required data and sharing their wisdom with us during the course of this research.

\section{REFERENCES}

[1] Screening donated blood for transfusion transmissible infections - Recommendations report 2009. World Health Organization 2009.

[2] Siraj N, Achila 00, Issac J, et al. Seroprevalence of transfusion-transmissible infections among blood donors at National Blood Transfusion Service, Eritrea: a seven-year retrospective study. BMC Infectious Diseases 2018;18(1):264.

[3] HIV data and statistics report 2018, World Health Organization 2018.

[4] Hepatitis report 2018, World Health Organization 2018. 
[5] Korenromp EL, Mahiane GS, Nagelkerke N, et al. Syphilis prevalence trends in adult women in 132 countries estimations using the spectrum sexually transmitted infections model. Scientific Reports 2018;8:11503.

[6] Fernandes H, D'souza PF, D'souza PM. Prevalence of transfusion transmitted infections in voluntary and replacement donors. Indian Journal of Hematology and Blood Transfusion 2010;26(3):89-91.

[7] Blood transfusion safety 2018, World Health Organization 2018.

[8] Giriyan SS, Chethana HD, Sindhushree N, et al. Study of utilization of blood and blood components in a tertiary care hospital. J Blood Lymph 2017;7:169.

[9] Ambroise MM, Ravichandran K, Ramdas A, et al. A study of blood utilization in a tertiary care hospital in South India. J Nat Sci Biol Med 2015;6(1):106-10.

[10] Chowdhury FS, Siddiqui A, Islam K, et al. Use of blood and blood components in Dhaka medical college hospital. Bangladesh Journal of Medicine 2015;26(1):18-24.

[11] Okoroiwu HU, Okafor IM, Asemota EA, et al. Seroprevalence of transfusion-transmissible infections (HBV, HCV, syphilis and HIV) among prospective blood donors in a tertiary health care facility in Calabar, Nigeria: an eleven years evaluation. BMC Public Health 2018;18(1):645.

[12] Regar BC, Prakash S, Chhabra V, et al. Utilization of blood and blood components in tertiary care hospital in Southern Rajasthan. International Journal of Current Advanced Research 2018;7(4):11998-12000.
[13] Qureshi MZ, Sawhney V, Bashir H, et al. Utilisation of blood components in a tertiary care hospital. International Journal of Current Research and Review 2015;7(22):1-7.

[14] Mathew AS, Kurian SS, Sundaresan NP, et al. Pattern of blood component utilization in a teaching hospital in South Kerala. Academic Medical Journal of India 2014;2(1):28-31.

[15] Katkoria SK, Agravat AH, Dhruva GA. A pilot study of utilization of blood components at tertiary care centre, Rajkot. APALM 2018;5(10).

[16] Okoroiwu HU, Okafor IM. Demographic characteristics of blood and blood components transfusion recipients and pattern of blood utilization in a tertiary health institution in southern Nigeria. BMC Hematology 2018;18:16.

[17] Kafle SU, Jha KK, Singh M, et al. Analysis of blood transfusion request and utilization pattern at teaching hospital in Eastern Nepal. J Pathol Nepal 2018;8:1374-7.

[18] Rahman MM, Saha D, Saha S, et al. Blood transfusion requests: an audit in a blood transfusion wing of a referral laboratory. JAFMC Bangladesh 2015;11(2):3-6.

[19] Kumar A, Sharma SM, Ingole NS, et al. Analysis of reasons for discarding blood and blood components in a blood bank of tertiary care hospital in central India: a prospective study. International Journal of Medicine and Public Health 2014;4(1):72-4.

[20] Arora I, Singh S, Singh S. Donor blood wastage: a study from blood bank Chamba (H.P). Int J Community Med Public Health 2018;5(7):3016-9. 